\title{
A comparison of phenytoin and valproate in previously untreated adult epileptic patients
}

\author{
DM TURNBULL, $*$ MD RAWLINS, $\dagger$ D WEIGHTMAN, $\ddagger$ DW CHADWICK \\ From the Department of Neurology, ${ }^{*}$ Royal Victoria Infirmary, Newcastle upon Tyne, the Department of \\ Clinical Pharmacology, $\dagger$ University of Newcastle upon Tyne, the Department of Medical Statistics, $\ddagger$ \\ University of Newcastle upon Tyne, and the Department of Neurology, $§$ Walton Hospital, Liverpool
}

SUMMARY Eighty-eight patients with the onset of epilepsy in adult life were randomly allocated to treatment with sodium valproate $(600 \mathrm{mg} /$ day $)$, or phenytoin $(300 \mathrm{mg} / \mathrm{day})$, and followed up for at least 12 months. Both drugs were highly effective in the control of tonic-clonic seizures, irrespective of whether they were accompanied by focal features, but were markedly less effective in the control of partial seizures. Two patients exhibited acute allergic reactions to phenytoin. No significant differences have yet emerged in the efficacy of the two drugs, and valproate may be considered as a "first-line" anticonvulsant in the treatment of adult onset epilepsy.

Although the evaluation of anticonvulsant therapy in epileptic patients over the years has been unsatisfactory, ${ }^{1}$ recent studies have demonstrated that with serum anticonvulsant level monitoring, approximately $80 \%$ of patients with adult onset epilepsy can be rendered seizure-free by treatment with either phenytoin or carbamazepine. ${ }^{23}$ These results have encouraged the use of single drugs in the management of epilepsy rather than polypharmacy, ${ }^{4}$ but there is little information as to which anticonvulsant drugs are most effective when given alone.

Sodium valproate (sodium di-n-propylacetate) possesses anticonvulsant activity in both animals and man. ${ }^{5}$ It is effective in the control of generalised and partial seizures and is particularly valuable in the treatment of generalised seizures in childhood. ${ }^{6}$ Its place in the treatment of adult onset epilepsy is less certain, and few studies have reported on the use of valproate alone, in the management of adult patients. ${ }^{78}$ Furthermore, little data is available to allow one to compare the efficacy of valproate as a single drug, with that of other more conventional anticonvulsants.

Phenytoin is a well established "first-line" anticonvulsant, although it is associated with many chronic toxic effects. ${ }^{9}$ We report the results of a com-

Address for reprint requests: Dr DW Chadwick, Walton Hospital, Rice Lane, Liverpool L9 1 AE, UK.

Received 30 September 1981

Accepted 8 October 1981 parative study of valproate and phenytoin in newly diagnosed, adult epileptic patients who have been followed up for 12 months.

\section{Methods}

Patients over the age of 16 years, with a clear history of two or more epileptic seizures in the previous 3 years, were randomised to therapy with either sodium valproate or phenytoin, after stratification for age, sex, and type of seizure. Three age groupings were used, that is 16-25, 26-65, 65 years or older. Patients were allotted to a tonicclonic seizure group if there was no positive clinical evidence of a focal onset or aftermath to the seizure. Other groups consisted of patients with complex partial seizures with or without secondarily generalised seizures, and simple partial seizures with or without secondary generalisation. Inclusion in the first group does not indicate that all patients had "primary generalised epilepsy". Indeed some of these patients had focal EEG abnormalities.

On entry to the study patients were routinely investigated with a skull radiograph and electroencephalogram (EEG). Further neurological investigation was undertaken as clinically indicated. Prior to therapy estimations of haemoglobin, white cell count, platelet count, MCV, serum B12 and folate, and red cell folate were carried out. Plasma urea, creatinine, serum calcium and alkaline phosphatase, bilirubin, aspartate transaminase, and serum albumin and globulin concentrations were also measured.

Patients were commenced on therapy with either sodium valproate (600 $\mathrm{mg}$ per day, in three divided doses) or phenytoin ( $300 \mathrm{mg}$ per day, in three divided doses), within 3 months of their last seizure. Follow-up was at 
3 month intervals after the initiation of therapy, although patients were seen more frequently in some cases where this was indicated. At each visit the occurrence of seizures or side-effects were documented and serum anticonvulsant levels estimated. Compliance was estimated by counts of tablets returned to the pharmacy. At 6 month intervals following the commencement of therapy haematological, and biochemical screening were repeated as above.

If further seizures occurred during the follow-up period the dose of anticonvulsant was increased. For patients receiving phenytoin, the daily dose was increased by 50 $\mathrm{mg}$ if the previous plasma level was below $10 \mu \mathrm{g} / \mathrm{ml}$ (40 $\mathrm{mmol} / \mathrm{l}$ ), and by $25 \mathrm{mg}$ if the level was $10 \mu \mathrm{g} / \mathrm{ml}$ (40 $\mathrm{mmol} / \mathrm{l})$ or greater. Increments were administered until seizures were controlled or clinical signs of intoxication occurred, irrespective of the serum level.

Patients who had further seizures whilst taking valproate received sequential increments to $1.2 \mathrm{~g} /$ day, $2 \cdot 1 \mathrm{~g} /$ day, and $3 \mathrm{~g} /$ day (in three divided doses), until there were no seizures or unacceptable adverse effects developed.

An individual drug was only regarded to have "failed" if the patient suffered unacceptable side-effects, or when seizurescontinued at doses up to those which caused doserelated side-effects, or in the case of valproate seizures continued in spite of treatment with a maximum dose of $3 \mathrm{~g} /$ day.

\section{Results}

One hundred and three patients were entered into the study 12 months or more before the date of analysis. Fifty-two of these were allocated to therapy with valproate, and 51 to therapy with phenytoin. Eleven patients were lost to follow-up, eight from the valproate group and three from the phenytoin group. All were seizure-free, and without side effects at the last followup they attended. Four patients died within thefollowup period, two from intracranial tumours diagnosed after randomisation, one from stroke, and one from myocardial infarction. Of these four patients, two had been allocated to therapy with valproate and two to phenytoin. Of the remaining 88,51 had a history of tonic-clonic seizures without focal features ( 23 were treated-with valproate, and 28 with phenytoin) and 32 patients had complex partial seizures with or without secondary generalisation (16 received therapy with valproate, and 16 with phenytoin). Five patients had symptoms of simple partial seizures with or without secondary generalisation, and for the present analysis these have been included with the complex partial seizure group.

\section{TONIC-CLONIC SEIZURES WITHOUT FOCAL}

FEATURES

Table 1 illustrates that there was no difference in the sex, age and EEG abnormalities of patients in the two therapeutic groups. There were no significant differences between valproate and phenytoin treated groups for the length of history of epilepsy, the frequency of seizures, and the number of seizures prior to therapy (Mann-Whitney U test).

Table 2 illustrates the outcome of drug therapy in these groups of patients. Nineteen $(83 \%)$ patients receiving valproate remained seizure-free during the first 12 months of therapy. Four $(17 \%)$ had further seizures at 3 to 9 (mean $4 \cdot 8$ ) months after the initiation of therapy and required an increase in dosage. Three patients were controlled at the first dosage increment of valproate $(1.2 \mathrm{~g} /$ day $)$ for periods of between 6 and 18 months. One patient had a further seizure 3 months after the first dosage increment of valproate and required a second increment to $2 \cdot 1 \mathrm{~g}$ /day, but has been followed for 9 months without further seizures. In this group a total of eight seizures occurred in the 12 months of therapy, compared with 72 in the same period before treatment, that is a reduction of $89 \%$.

Twenty $(71 \%)$ phenytoin-treated patients remained seizure-free. Six (21\%) patients required an increase in phenytoin dosage because of further seizures occurring one to 6 months (mean 4.6) after the start of therapy. Two patients remained seizure-free after the first dosage increment of phenytoin for periods of 9 and 12 months respectively. Four patients required a second increment of phenytoin because of further seizures, which occurred between one and 6 months (mean 2.8) after the first increment. Three of these patients have subsequently been followed for a further 12 months without fits, but one has continued to have seizures up to doses sufficient to cause acute phenytoin toxicity (ataxia, dysarthria, and nystagmus). Two patients were withdrawn from phenytoin therapy shortly after commencement. In

Table 1 Patients with tonic-clonic seizures (without focal features)

\begin{tabular}{|c|c|c|c|c|c|c|c|c|}
\hline & \multicolumn{2}{|c|}{ Sex } & \multirow{2}{*}{$\begin{array}{l}\text { Age (yr) } \\
\text { Range (mean) }\end{array}$} & \multicolumn{3}{|c|}{$E E G$} & \multirow{2}{*}{$\begin{array}{l}\begin{array}{l}\text { No seizures } \\
\text { pretreatment }\end{array} \\
\text { Range (median) }\end{array}$} & \multirow{2}{*}{$\begin{array}{l}\begin{array}{l}\text { Length of history (months) } \\
\text { pretreatment }\end{array} \\
\text { Range (median) }\end{array}$} \\
\hline & $M$ & $F$ & & $N$ & $G$ & $F$ & & \\
\hline $\begin{array}{l}\text { Valproate } \\
\text { Phenytoin }\end{array}$ & $\begin{array}{l}11 \\
15\end{array}$ & $\begin{array}{l}12 \\
13\end{array}$ & $\begin{array}{l}16-64(31) \\
16-67(33)\end{array}$ & $\begin{array}{l}16 \\
22\end{array}$ & $\begin{array}{l}4 \\
2\end{array}$ & $\begin{array}{l}3 \\
4\end{array}$ & $\begin{array}{l}2-20(3 \cdot 5) \\
2-8(3 \cdot C)\end{array}$ & $\begin{array}{l}1-192(8.5) \\
1-60(6.0)\end{array}$ \\
\hline
\end{tabular}

$\mathbf{N}=$ normal or non-specific abnormality.

$\mathbf{G}=$ generalised paroxysmal abnormality。

$F=$ focal paroxysmal abnormality. 
Table 2 Outcome of therapy-patients with tonic-clonic seizures

\begin{tabular}{lllcc}
\hline & Fit-free & Further fits & Failed & Total \\
\hline Valproate & $19(83 \%)$ & $4(17 \%)$ & 0 & 0 \\
Phenytoin & $20(71 \%)$ & $5(18 \%)$ & $1(4 \%)$ & 23 \\
\hline
\end{tabular}

Column 1 vs columns $2+3$, exact probability test $p=0.73$ (NS).

Further fits-seizures occurring after the commencement of therapy, but subsequently controlled on an increased dose.

Failed-continued seizures in spite of increases in dosage sufficient to cause toxicity.

one case this was due to a maculo-papular rash, and in the other because of an acute erythroderma, associated with jaundice and disturbed liver function tests. In both cases withdrawal of phenytoin resulted in a rapid improvement in symptoms and the subjects subsequently tolerated valproate well.

In this group there were 74 tonic-clonic seizures in the 12 months prior to treatment, compared with 24 in the same period after treatment (15 of these were in the same patient) that is a reduction of $68 \%$.

PARTIAL SEIZURES (WITH OR WITHOUT SECONDARY GENERALISATION)

Table 3 illustrates that there is no difference in sex, age and the EEG findings in the patients in the two treatment groups. The groups do not differ significantly for the number of seizures, the length of the history and the frequency of seizures in the 12 months prior to therapy (Mann-Whitney $U$ test).

Table 4 gives the response to therapy with valproate and phenytoin in patients with partial seizures. Of 20 patients treated with valproate six $(30 \%)$ remained seizure-free on the initial dose of valproate, but 14 patients $(70 \%)$ experienced further seizures. These occurred at one to 12 months after the initiation of therapy (mean 5.2 months). Seven of these patients have subsequently been controlled on an increased dose of $1.2 \mathrm{~g} /$ day of valproate for between 7 and 16 months (mean 10 months). One of these patients however developed hair loss and was withdrawn from valproate in spite of good seizure control. Seven patients continued to have seizures whilst receiving $1.2 \mathrm{~g} /$ day valproate. These seizures occurred at one to 3 (mean 1.7) months following the dosage increment to $1.2 \mathrm{~g} /$ day. One patient remained seizure-free for 6 months following a second dosage increment, but developed hair-loss necessitating valproate withdrawl. One patient has remained controlled on a dose of $3 \mathrm{~g}$ /day valproate for a period of 6 months, but $5(25 \%$ of the whole group) patients have continued to have seizures in spite of doses of valproate of $2 \cdot 1 \mathrm{~g} /$ day in three patients, and $3 \mathrm{~g} /$ day in two patients, which caused the development of a characteristic syndrome of intoxication. This consisted of the development of a fine postural tremor, motor restlessness and irritability, and in three patients excessive weight gain. Thus, some seven $(35 \%)$ patients with partial seizures treated

Table 3 Patients with partial seizures

\begin{tabular}{|c|c|c|c|c|c|c|c|c|}
\hline & \multicolumn{2}{|c|}{ Sex } & \multirow{2}{*}{$\begin{array}{l}\text { Age (yr) } \\
\text { Range (mean) }\end{array}$} & \multicolumn{3}{|c|}{$E E G$} & \multirow{2}{*}{$\begin{array}{l}\begin{array}{l}\text { No seizures } \\
\text { pretreatment }\end{array} \\
\text { Range (median) }\end{array}$} & \multirow{2}{*}{$\begin{array}{l}\text { Length of history (months) } \\
\text { pretreatment }\end{array}$} \\
\hline & $M$ & $\boldsymbol{F}$ & & $N$ & $G$ & $F$ & & \\
\hline Valproate & 9 & 11 & $16-65(36)$ & 10 & 0 & 10 & $\begin{array}{l}\text { a. } 2-360(10) \\
\text { b. } 0-12(1 \cdot 5)\end{array}$ & $1 \cdot 5-132(15)$ \\
\hline Phenytoin & 10 & 7 & $26-63(40)$ & 9 & 0 & 8 & $\begin{array}{l}\text { a. } 2-360(10) \\
\text { b. } 0-30(3.0)\end{array}$ & $1-360(12)$ \\
\hline
\end{tabular}

$\mathbf{N}=$ normal or non-specific abnormality. $\quad a=$ partial seizures.

$\mathbf{G}=$ generalised paroxysmal abnormality. $\quad$ b $=$ secondary tonic-clonic seizures.

$F=$ focal paroxysmal abnormality.

Table 4 Outcome of therapy-patients with partial seizures

\begin{tabular}{lllll}
\hline & Fit-free & Further fits & Failed & Early withdrawal \\
\hline Valproate & $6(30 \%)$ & $7(35 \%)$ & $7(35 \%)$ & 0 \\
Phenytoin & $6(35 \%)$ & $8(47 \%)$ & $3(18 \%)$ & 0 \\
\hline
\end{tabular}

Column 1 vs columns $2+3$, exact probability test $p=1.00$ (NS).

Columns $1+2$ vs column 3 , exact probability test $p=0.29$ (NS).

Further fits-seizures occurring after the commencement of therapy but subsequently controlled on an increased dose.

Failed-continued seizures in spite of increases in dosage sufficient to cause toxicity. 
with valproate have been withdrawn from the drug during the first 12 months of therapy because of either failure of seizure control, or the development of untoward side-effects at doses necessary to achieve seizure control.

In the 12 months after the commencement of valproate there were 74 partial seizures compared to approximately 310 in the 12 months prior to therapy, a reduction of $75 \%$. Of the 14 patients experiencing further seizures on valproate, only four had a total of five secondarily generalised fits, a reduction of $85 \%$ in the number of such seizures, compared to the 12 months before treatment. Twelve patients who had tonic-clonic seizures prior to treatment had no such attacks whilst taking valproate.

Of 17 patients with partial seizures treated with phenytoin six $(35 \%)$ have remained seizure-free during the period of follow-up. Eleven $(65 \%)$ had further seizures at between one and 3 months (mean 2.0 months) after the initiation of therapy. An initial dose increase of phenytoin to $350 \mathrm{mg}$ daily resulted in control in four more patients for periods of between 9 and 15 months. Seven patients experienced further seizures between one and 9 months (mean 4.0 months) after the dose of phenytoin was increased to $350 \mathrm{mg}$ daily. Of these seven patients further increases of dosage up to 375 or $400 \mathrm{mg}$ of phenytoin daily resulted in control in three patients for periods of 3,9 and 15 months. One patient has had further seizures whilst taking both $\mathbf{4 0 0}$ and $\mathbf{4 5 0}$ $\mathrm{mg}$ of phenytoin daily and is subsequently being followed up taking a dose of $\mathbf{4 7 5} \mathrm{mg}$ daily. Three patients ( $18 \%$ of the whole phenytoin-treated group) have continued to have seizures up to doses of 375 , 400 and $475 \mathrm{mg}$ daily, which caused symptoms and signs of phenytoin intoxication.

In this group of patients there were 66 partial seizures in the 12 months after the commencement of phenytoin compared to approximately 145 in the same period prior to treatment, a reduction of $54 \%$. Of the 11 patients with further seizures on phenytoin only two patients had a total of five further tonicclonic seizures, a reduction of $90 \%$ in the number of such seizures. Twelve patients who had tonic-clonic seizures prior to therapy had no such attacks on treatment.

\section{COMPLIANCE}

Data on compliance is incomplete, as some patients persistently failed to return unused tablets to the pharmacy. Some patients were obviously noncompliant on the basis of their plasma drug levels, but all these subsequently failed follow-up, and have therefore been excluded from the present analysis. No patient included in this analysis ever had a recorded compliance of less than $75 \%$, and there was no major difference between the compliance of the two groups.

\section{HAEMATOLOGICAL AND BIOCHEMICAL PARAMETERS}

Changes in haematological and biochemical parameters were examined by comparison of pre-treatment values with values obtained after one year on treatment using Student's paired $t$ test. Small but statistically significant changes were seen in the case of phenytoin where there was an increase of mean cell volume $(p<0.05)$, and reductions in serum folate $(p<0.01)$, red cell folate $(p<0.001)$, calcium $(p<0.05)$, and albumin $(p<0.05)$. For valproate there was again a small but statistically significant increase in mean cell volume $(p<0.05)$, and reduction in red cell folate $(p<0.01)$, and in serum albumin $(p<0.001)$. No significant changes were noted in any other parameters, and with the exception of the single patient with phenytoin induced hepatotoxicity, no haematological or biochemical parameters deviated at any time from the normal range.

\section{Discussion}

The preliminary data from this study do not suggest any major differences in the efficacy of valproate and phenytoin in adult onset epilepsy. The groups of patients randomised to valproate and phenytoin are comparable in all major respects: that is for age, sex, proportion of patients with EEG abnormalities, and length of history and the severity of epilepsy prior to therapy. Furthermore, the followup periods which have been compared were identical, that is $\mathbf{1 2}$ months for each patient, thus enabling statistical analysis of our data. Although preexisting plasma levels of phenytoin were used to determine the size of increments of phenytoin dosage (which was not the case for valproate) neither drug was regarded to have "failed" unless seizures continued up to doses sufficient to cause adverse reactions.

The results for phenytoin are very similar to previously published data on the use of phenytoin as sole anticonvulsant therapy. ${ }^{2} 3$ In these studies phenytoin was highly effective in suppressing tonicclonic seizures whether or not these occurred in association with partial seizures. However the drug was markedly less effective in the control of partial seizures particularly when these appeared to have a temporal lobe origin. The data from this study suggests a similar spectrum of efficacy for valproate.

Valproate and phenytoin were most effective in that group of patients who at the time of randomisation had symptomatology only of tonic-clonic seizures. This group is certainly not homogeneous and 
is likely to contain many patients have a partial epilepsy as well as those with generalised epilepsy. So far, however, the finding of a focal EEG abnormality in this group does not appear to predict a poorer response to drug therapy. Failure of control occurred twice as often in patients with partial seizures receiving valproate. Although this difference is not statistically significant, further follow-up may show phenytoin to be a more effective drug in this group of patients.

Valproate and phenytoin did not differ in their effect on haematological, and biochemical parameters, with the exception that phenytoin reduced serum calcium whilst valproate did not. It is interesting that both phenytoin and valproate have effects on mean cell volume and red cell folate levels, in spite of the major differences in the structure of these two drugs. No major changes in liver function tests have been evident in the series of patients treated with valproate, in spite of previous reports of hepatotoxicity with valproate. ${ }^{1011}$ Indeed only one patient, receiving phenytoin, has shown evidence of hepatotoxicity during the course of this study. Both drugs have been relatively well tolerated by patients and in only two cases has an anticonvulsant drug had to be withdrawn early in the course of therapy because of a drug-induced skin reaction (phenytoin in both cases).

Few studies have reported the use of valproate as a sole anticonvulsant agent. ${ }^{7}$ In the majority of patients thus treated so far there has been a predominance of childhood epilepsy, and the present study represents the first major study of valproate in previously untreated adult onset epilepsy. The demonstration of a similar efficacy of valproate and phenytoin is in keeping with the report of Shakir et al, ${ }^{8}$ who studied a smaller number of patients, with a varying period of follow-up which made the statistical comparison of treatment groups difficult.

At high doses of valproate ( $1.2 \mathrm{~g} /$ day and above) some symptoms of apparently dose-related toxicity were seen. These consisted of excessive weight gain, hair loss and tremor, all of which have been previously associated with valproate treatment. ${ }^{12} 13$ However, some mental state changes were also seen which consisted of motor restlessness and irritability, often associated with some form of affective change. These latter effects tended to be subtle and to develop with a latent period of two or three months after an increment of valproate. They were however consistently relieved by subsequent withdrawal of this drug. Other patients have previously been described taking valproate alone, who developed not dissimilar mental state changes. ${ }^{14}$ Symptoms of dose-related toxicity were only seen with plasma valproate levels greater than $90 \mu \mathrm{g} / \mathrm{ml}(630 \mathrm{mmol} / \mathrm{l})$.
In conclusion, preliminary results from the first year's treatment with valproate would suggest that it is as effective as phenytoin, and can reasonably be used as an anticonvulsant of first choice in adult onset epilepsy. More prolonged follow-up is, however, necessary to confirm these results. Such longer term comparisons of individual anticonvulsant drugs used as sole therapy are required to enable a more rational use of both old and new anticonvulsant drugs.

We are grateful to all those physicians who kindly referred patients for inclusion in this study, to Labaz for financial support, and to Professor DA Shaw and Dr EH Reynolds for their helpful criticism and advice. DMT is in receipt of an MRC Training Fellowship.

\section{References}

${ }^{1}$ Coatsworth JJ. Studies on the clinical efficacy of anticonvulsant drugs. NINDS Monograph 1971 No 12.

${ }^{2}$ Reynolds EH, Chadwick DW, Galbraith AW. One drug (phenytoin) for the treatment of epilepsy. Lancet 1976;1 :923-6.

${ }^{3}$ Shorvon SD, Chadwick DW, Galbraith AW, Reynolds EH. One drug for epilepsy. Br Med J 1978;2:474-6.

${ }^{4}$ Reynolds EH, Shorvon SD. Monotherapy or polytherapy for epilepsy. Epilepsia $1981 ; 22: 1-10$.

${ }^{5}$ Simon D, Penry JK. Sodium di-N-propylacetate (DPA) in the treatment of epilepsy. Epilepsia 1975; 16:549-73.

6 Jeavons PM, Clark JE, Maheshwari MC. Treatment of generalised epilepsies of childhood and adolescence with sodium valproate (Epilim). Develop Med Child Neurol 1977;19:9-25.

7 Pinder RM, Brogden RN, Speight TM, Avery GS. Sodium valproate: A review of its pharmacological properties and therapeutic efficacy in epilepsy. Drugs 1977;13:81-123.

${ }^{8}$ Shakir RA, Johnson RH, Lambie DG, Melville ID, Nanda RN. Comparison of sodium valproate and phenytoin as single drug treatment in epilepsy. Epilepsia 1981 ;22:27-33.

9 Reynolds EH. Chronic antiepileptic toxicity: A review. Epilepsia 1975;16:319-52.

10 Ware S, Millward-Sadler GH. Acute liver disease associated with sodium valproate. Lancet 1980;2: 1110-3.

11 Coulter DL, Wu H, Allen RJ. Valproic acid therapy in childhood epilepsy. JAMA 1980;244:785-8.

12 Hassan MN, Laljee HCK, Parsonage MJ. Sodium valproate in the treatment of resistant epilepsy. Acta Neurol Scand 1976:54:209-18.

13 Hyman NM, Dennis PD, Sinclair KGA. Tremor due to sodium valproate. Neurology (Minneap) 1979;29: 1177-80.

${ }^{14}$ Chadwick DW, Cumming WJK, Livingstone I, Cartlidge NEF. Acute intoxication with sodium valproate. Ann Neurol 1979;6:552-3. 